\title{
Janus particles by simplified RAFT-based emulsion polymerization process for polymer coating
}

\author{
Duc Nguyen $^{1}$ (D) Vien T. Huynh ${ }^{1} \cdot$ Algirdas K. Serelis $^{2} \cdot$ Tim Davey $^{2} \cdot$ Olga Paravagna $^{2} \cdot$ Chris H. Such $^{2}$. \\ Brian S. Hawkett ${ }^{1}$
}

Received: 15 November 2021 / Revised: 22 December 2021 / Accepted: 22 December 2021 / Published online: 11 January 2022

(c) The Author(s) 2022

\begin{abstract}
We describe a simplified method to synthesize film forming polymer Janus particles by phase separation during RAFT-based free radical emulsion polymerization. Fully crosslinked snowman- or football-shaped polystyrene Janus particles (PSJPs) were first produced in a one-step batch process using amphiphilic triblock macro-RAFT copolymers as stabilizers. Such particles were in turn employed as seeds in a continuous emulsion polymerization in which a monomer mixture of methyl methacrylate (MMA) and butyl acrylate (BA) (1/1 by weight) was constantly injected into the reaction in the presence of a water soluble initiator. The added monomers wetted seed particle surface and their polymerization led to formations of 93-nm film forming single- or two-headed Janus particles. The resulted latex was successfully used to disperse and encapsulate solid calcite extender.
\end{abstract}

Keywords Encapsulation $\cdot$ Two-headed snowman $\cdot$ Snowman $\cdot$ Janus particles

\section{Introduction}

Professor Masayoshi Okubo was a highly respected figure in polymer colloidal science who tirelessly worked to advance the field even after his retirement. His interests covered multiple areas from polymerization mechanisms in dispersed phase [1-3] to synthesis of advanced structures [4, 5] such as hollow particles [6, 7] and nanocomposites [8]. One major contribution by Prof Okubo has been the work on polymer Janus structures in dispersed media [9-16]. Janus particles contain two or more phases with distinct chemical or physical properties [17]. One of the most notable works by Prof Okubo's group is the synthesis of snowman-like particles based on enhanced phase separation between incompatible poly(methyl methacrylate) (PMMA) and polystyrene (PS) in droplet dispersion when a good solvent (toluene) for both

Duc Nguyen

david.nguyen@sydney.edu.au

Brian S. Hawkett

brian.hawkett@sydney.edu.au

1 Key Centre for Polymers and Colloids, School of Chemistry, University of Sydney Nano Institute, The University of Sydney, Sydney, NSW 2006, Australia

2 DuluxGroup Australia, Clayton, VIC 3168, Australia was slowly removed [14]. This work was based on their previous publication in which multiple scenarios for possible Janus structural configurations were explored using solvent evaporation-induced phase separation [15]. This established the foundation for their further developments of well-known micron-sized monodispersed mushroom-like particles [12] which could be engineered to be temperature sensitive and useful as dispersing agents. The method now serves as one of common tools [17] for Janus particle synthesis.

In honoring professor Okubo contributions, our latest development on the synthesis of polymer Janus nanoparticles is presented here. Our method is based on the use of crosslinked seeds and polymer phase separation during polymerization as originally set out by Sheu et al. [18]. In this technique, phase separation is induced by heating the monomer-swollen crosslinked seeds to an elevated temperature at which the crosslinked networks contract and expel the monomers to the particle interface [18]. The monomers spread on the surface of the seeds and, following free radical emulsion polymerization, produce polymer domains attached to the seeds. This results in the formation of asymmetric Janus morphologies (rather than non-core-shell particles). Crosslinking degree and the nature of the seed particle surface are important factors influencing final product shapes, from ellipsoidal to snowman-shaped [18, 19]. This strategy was successfully employed by others $[17,19-23]$ to synthesize 
of Janus/anisotropic particles with different size $[19,21]$ and chemical composition [17, 21,22], which were found to be useful as stabilizers for emulsification [17, 21, 22]. However, various limitations such as large seed sizes, monomer swelling requirement, complex post modification process (to become surface active), and low solid contents have been restricted possible scale-up. Recent advancements in controlled living free radical emulsion polymerization show potential to address these drawbacks [24-26]. By combining RAFT-based polymerizationinduced self-assembly (PISA) and the principle developed by Sheu et al. [18], Pham et al. [26] synthesized 25-nm amphiphilic football- and snowman-shaped particles which were useful as stabilizers for subsequent surfactant-free emulsion polymerization of MMA and BA. Lotierzo et al. [25] used sulfur-free RAFT polymerization to make nanogels and subsequently Janus or patchy particles of between 70 and $200 \mathrm{~nm}$ in sizes. However, the mentioned works still involves multiple steps, especially the time-consuming swelling step in the case of Pham et al. [26], which is an obstacle for potential scaling-ups. In a bid to eliminate the requirement for a separate step of monomer swelling, a continuous process was developed in our recent work [27] in which monomers were constantly supplied into free radical emulsion polymerization using RAFT-PISA-based crosslinked PS seeds. The synthesized 40-nm snowman latex with a solid content above $30 \%$ was found to be amphiphilic and particularly useful to uniformly encapsulate solid particles such as pigments, calcite extender to carbon nanotubes [27]. However, the process still consisted of three steps: seed synthesis, seed crosslinking, and polymer lobe formation to make snowman structures. In this work, we demonstrate the ability to use RAFT-based emulsion polymerization to synthesize snowman-shaped Janus particles in one step. The latex particles were subsequently used as the seeds in a continuous process to make film forming two-headed snowman-shaped particles for polymer coating application.

\section{Experimental section}

\section{Materials}

Milli-Q water was used in the synthesis of all latexes. Acrylic acid (AA), methyl methacrylate (MMA), butyl acrylate
(BA), styrene (Sty), divinyl benzene (DVB, $80 \mathrm{wt} \%$ pure), 1,4-dioxane, 4,4'-azobis(4-cyanovaleric acid) (V501), and propylene glycol were obtained from Sigma-Aldrich (Castle Hill, Australia). MMA, BA, and Sty had the inhibitor removed by passing the monomer through an inhibitor removal column (Aldrich). 2,2'-Azobisisobutyronitrile (AIBN, Fluka) was recrystallized from ethanol. The RAFT agent, dibenzyl trithiocarbonate (DBTC) (see Fig. 1, Dulux Australia) was used as received. Ammonium hydroxide (25\% $\mathrm{NH}_{3}$ in water, w/w) was purchased from Ajax Finechem (Sydney, Australia). Calcite, Omyacarb $10(\sim 10 \mu \mathrm{m})$ (Omya Australia), and Teric 164 non-ionic surfactant were supplied by DuluxGroup Australia and used without modifications.

\section{Synthesis of macro-RAFT triblock D with [Sty]/[BA]/ [AA]/[DBTC] 80/120/60/1}

Macro-RAFT triblock D (Fig. 1) was prepared in the same manner as in previous works $[28,29]$. The RAFT agent, DBTC, (0.62 g, $2.2 \mathrm{mmol})$ was mixed with AIBN $(0.1 \mathrm{~g}$, $0.6 \mathrm{mmol}), \mathrm{AA}(9.2 \mathrm{~g}, 127.4 \mathrm{mmol}), \mathrm{BA}(33.0 \mathrm{~g}, 257.7 \mathrm{mmol})$, and dioxane $(40.0 \mathrm{~g})$ in a $250-\mathrm{mL}$ round bottom flask. The yellow solution was sealed, purged with nitrogen for $10 \mathrm{~min}$, and then heated at $70{ }^{\circ} \mathrm{C}$ for $3 \mathrm{~h}$ under constant stirring. After heating, the sample was found to have $49 \%$ solids with $94 \%$ conversion. Sty (17.8 g, $170.0 \mathrm{mmol})$ and AIBN $(0.1 \mathrm{~g}, 0.6 \mathrm{mmol})$ were subsequently added to this polymer solution. The reaction was again sealed, deoxygenated with nitrogen for $15 \mathrm{~min}$, and then heated at $70{ }^{\circ} \mathrm{C}$ for another $12 \mathrm{~h}$ under constant stirring. After heating, the product contained $53.0 \%$ solids (calculated Sty conversion of 59.8\%) unreacted Sty estimated to be $7.1 \%$. This triblock D polymer solution was used as is without solvent or monomer removal throughout all the experiments to mimic practices during industrial scale-up.

\section{Synthesis of crosslinked polystyrene Janus particles (PSJPs) using RAFT emulsion polymerization}

Triblock D macro-RAFT solution (10.0 g) was mixed with water $(500.0 \mathrm{~g})$ containing ammonium hydroxide $(1.6 \mathrm{~g}$, $25 \%$ in water) in a 1-L beaker to yield a yellow solution
Fig. 1 a RAFT agent dibenzyl trithiocarbonate (DBTC) and $\mathbf{b}$ triblock D macro-RAFT copolymers used as the stabilizer for Janus particle synthesis a. Dibenzyltrithiocarbonate (DBTC)

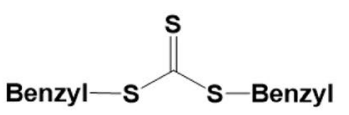

\section{b. Triblock D}

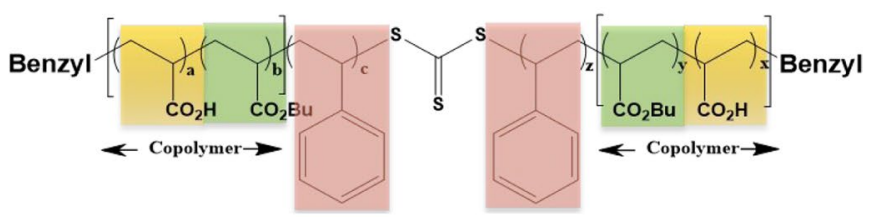


Table 1 Summary of Janus particle synthesis

\begin{tabular}{lcccccccc}
\hline Sample name & Sty $(\mathrm{g})$ & $\begin{array}{l}\text { DVB }(80 \% \\
\text { pure })(\mathrm{g})\end{array}$ & $\begin{array}{l}\text { MMA/BA } \\
(1 / 1)(\mathrm{g})\end{array}$ & V501 $(\mathrm{g})$ & Triblock D $(\mathrm{g})$ & Seed latex $(\mathrm{g})$ & $\begin{array}{l}\text { Water }(\mathrm{g}) \\
\begin{array}{l}\text { Reaction } \\
\text { time }(\mathrm{h})\end{array}\end{array}$ \\
\hline PSJP & 25 & 2.5 & - & 0.15 & 10 & - & 500 \\
FFJP & - & - & 110.2 & 0.6 & - & 301 & 301 & 16.5 \\
\hline
\end{tabular}

with pH 9. Sty ( $25 \mathrm{~g}, 240 \mathrm{mmol})$ and DVB ( $2.5 \mathrm{~g}, 15 \mathrm{mmol})$ were added to the macro-RAFT solution and thoroughly dispersed by a mechanical stirrer (Labortechnik, IKA) for $10 \mathrm{~min}$ at $1000 \mathrm{rpm}$ to obtain yellow emulsion. The emulsion was transferred to a 1-L round bottom flask containing V501 $(0.15 \mathrm{~g}, 0.5 \mathrm{mmol})$ which was subsequently sealed and purged with nitrogen for $15 \mathrm{~min}$. The whole flask was then immersed in an oil bath with a temperature setting of $70{ }^{\circ} \mathrm{C}$ and was magnetically stirred. The reaction was carried out in $12 \mathrm{~h}$ to produce yellow latex with $6.2 \%$ solids, average particle size of $56 \mathrm{~nm}(0.1 \mathrm{PDI})$ and zeta potential of $-38 \mathrm{mV}$ (at pH 9) (Zetasizer, Malvern Instrument).

\section{Synthesis of film forming Janus particles (FFJPs) using crosslinked PSJPs as seeds}

PSJP latex (301 g) and water (301 g) was added to a 1-L round bottom flask containing V501 (0.6 g, $2 \mathrm{mmol})$. The flask was subsequently sealed and purged with nitrogen for $10 \mathrm{~min}$. The whole flask was then immersed in an oil bath with a temperature setting of $70{ }^{\circ} \mathrm{C}$ and was magnetically stirred. A deoxygenated MMA/BA mixture (1:1 by weight) $(50 \mathrm{~mL}, 45.9 \mathrm{~g})$ was injected into the flask, while in the $70{ }^{\circ} \mathrm{C}$ oil bath, at a rate of $20 \mathrm{~mL} / \mathrm{h}$. After $2.5 \mathrm{~h}$, another $70 \mathrm{~mL}(64.3 \mathrm{~g})$ monomer mixture of MMA/BA $(1: 1)$ was injected into the flask at a rate of $35 \mathrm{~mL} / \mathrm{h}$. Upon completion of feeding, the heating was continued for $12 \mathrm{~h}$ to produce white latex. The final latex had $17.5 \%$ solids with an average particle size of $93 \mathrm{~nm}(0.08 \mathrm{PDI})$ and surface charge zeta potential of $-30 \mathrm{mV}(\mathrm{pH}$ 8) (Zetasizer, Malvern Instrument). The glass transition temperature (Tg) of poly(MMA-co-BA) in the polymer lobes with MMA/BA monomer mixture of $1: 1$ was estimated to be $4{ }^{\circ} \mathrm{C}$ based on our previous work [27].

Particle size was measured by dynamic light scattering (DLS) on a Zetasizer (Nano-ZS, Malvern Instruments).
Samples were diluted with water to about $0.1 \%$ prior to measurements.

The morphology of the particles was studied using transmission electron microscopy (TEM, JEOL 1400), scanning electron microscopy (SEM, Zeiss Sigma HD FEG), and atomic force microscope (AFM, Bruker Multimode 8). TEM and SEM samples were prepared by depositing a drop of each sample prepared for DLS on TEM grids or SEM stubs. The samples were allowed to dry at room temperature prior to examination. For the AFM study, the same diluted sample was deposited and air dried on hydrophilic silicon wafer prior to imaging. Experimental conditions and final product characterization are summarized in Tables 1 and 2.

\section{Polymer coating of calcite using FFJPs}

Polymer coating of calcite Omyacarb 10 was carried out with the following procedure. FFJP latex ( $30.0 \mathrm{~g})$, propylene glycol $(8.5 \mathrm{~g})$, and Teric164 (0.3 g) were mixed in a beaker using an overhead mechanical stirrer. To this mixture, Omyacarb 10 (20.8 g, Omya Australia) was added and mixed for $5 \mathrm{~min}$ using a mechanical stirrer at $1500 \mathrm{rpm}$ to produce a viscous white dispersion. For TEM and SEM assessments, 1 drop of the dispersion was mixed with $2.5 \mathrm{~mL}$ of water in an Eppendorf tube. The sample was centrifuged and washed 3 times with water to remove un-adsorbed FFJPs. The coated calcite was then redispersed in $2.5 \mathrm{~mL}$ of water and used for SEM analysis. For TEM, a one tenth dilution of the dispersion was used. The same polymer coating was also carried out but without Teric 164 to check the effect on encapsulation in the absence of the surfactant.

For comparison purpose, Omyacarb 10 was blended with PSJP latex in a similar manner and characterized by SEM for particle adsorption evidence. SEM imaging of bare extender particles was also carried out to highlight differences between coated and uncoated surface.
Table 2 Sizes and morphologies in corresponding polymer latex

\begin{tabular}{llllll}
\hline Sample name & Size $(\mathrm{nm})$ & PDI & $\begin{array}{l}\text { Surface charge } \\
(\mathrm{mV})\end{array}$ & Solids (\%) & Morphologies \\
\hline Triblock D (pH 8.5) & 30 & 0.32 & -45 & & Micelle \\
PSJPs & 56 & 0.10 & -38 & 6.2 & Snowman/football \\
FFJPs & 93 & 0.08 & -30 & 17.5 & Snowman \\
\hline
\end{tabular}




\section{Results and discussion}

\section{Triblock macro-RAFT copolymers and all in one PSJP synthesis}

Triblock D was proven to be a versatile stabilizer for the synthesis of different morphologies from nanoparticles to nanofibers, hollow particles [29], and pigment encapsulation [28] using the PISA process. The macro-RAFT was synthesized from the RAFT agent DBTC (Fig. 1) which contains two identical benzyl leaving groups. Our previous studies [28, 29] showed that the triblock D synthesis was under RAFT control/living free radical polymerizations and produced well defined and narrowly distributed copolymers. Since the experimental conditions were kept the same as in our previous work [28], triblock D in this work had an estimated empirical structure of DBTC-Sty ${ }_{48^{-}}$ block-( $\left(\mathrm{BA}_{112}\right.$-co- $\left.\mathrm{AA}_{56}\right)(\mathrm{Mn}$ approximately $23,000 \mathrm{~g} / \mathrm{mol})$ based on the experimental conversions. If the two leaving groups equally participated in polymerization, triblock $\mathrm{D}$ molecular structure is approximated to be DBTC-[Sty ${ }_{24^{-}}$ block-( $\left.\left.\mathrm{BA}_{56}-\mathrm{Co}-\mathrm{AA}_{28}\right)\right]_{2}$. As mentioned above, the triblock D copolymer solution contained $53 \mathrm{wt} . \%$ polymer, $7 \mathrm{wt} . \%$ Sty, and 40 wt.\% dioxane and was used without further modification.

The emulsion polymerization was performed without surfactant and triblock D was the sole stabilizer/emulsifier. To emulsify, the triblock was first dispersed with ammonium hydroxide in water to neutralize the carboxylic groups on the AA units of the two copolymer ends. Once neutralized, the now amphiphilic triblock D self-assembled into micelles with an average size of $30 \mathrm{~nm}$ as measured by DLS. The micelles presumably consisted of a PS and PBA core and a negatively charged AA stabilizing corona. The cores were also swollen with Sty monomer as a part of the macro-RAFT polymer solution. Further monomer emulsification was carried out by a simple mixing of Sty and DVB with the macroRAFT dispersion by a mechanical overhead stirrer. The process produced a yellow emulsion containing large droplets $(\sim 5 \mu \mathrm{m}$, as measured in previous studies $[28,29])$ and monomer saturated micelles, all of which were stabilized by the triblock. After emulsification, crosslinked PSJPs were synthesized by heating the emulsion in the presence of watersoluble initiator V501 to produce a stable polymer latex having an average particle size of $56 \mathrm{~nm}$ (0.1 PDI, Table 2). As shown by TEM images in Figs. 2a and S1 (supporting information, SI), the final product contained two types of particles: a majority ( 5 out of 7 , or $\sim 70 \%$ ) having a snowman morphology characterized by the fusion of two spheres with different diameters and a minority ( 2 out of $7, \sim 30 \%$ ) of slightly elongated football-shaped particles. In Fig. S1b, snowman-shaped particles consist of approximately $70 \%$
(22 out of 32, excluding the one on edges) total population. Dimensions in Fig. 2b showed snowman-shaped particles were varied in size with the smaller heads between 10 and $40 \mathrm{~nm}$ and the bodies were found to be $20-60 \mathrm{~nm}$. Total heights also varied between 50 and $90 \mathrm{~nm}$, making them quite large from the side view. The football-shaped particles were much smaller at between approximately 40 and $60 \mathrm{~nm}$. Given the complexity of particle morphologies, the above size measurement of $56 \mathrm{~nm}$ by DLS should only be considered as an estimate due to the limit of measuring technique. The particle formation mechanism is schematically depicted in Fig. 2c. In the early stage of free radical emulsion polymerization, particles were formed from polymerization of existing or newly generated micelles by chain extensions of amphiphilic macro-RAFT copolymers. The presence of DVB might further accelerate the process by formation of crosslinking networks connecting all the triblock D together and set volume expansion limits for each particle. As the polymerization progressed, monomers uptake by swelling within the interior was prevented due to such rigid structures. Monomers, both Sty and DVB (supplied from large monomer droplets as reservoirs), would instead wet and undergo polymerization on the particle surface. The different sizes of protruded lobes are probably due to uneven monomer distribution and different surface wetting between particles. Particles with less monomers on the surface became football shaped. However, the majority of the particles were snowman shaped, which showed reasonable supply of Sty/ DVB for surface nucleation in most cases. As the starting triblock D dispersion contained micelles of $30 \mathrm{~nm}$ on average, snowman bodies (20-60 nm) were expected to form first prior to creations of smaller snowman heads (10-40 nm) as the attached crosslinked polymer lobes. Throughout polymerization process, particles stability was maintained despite the surface area increase due to polymer lobe growths. This was probably due to the imparted negative charge from the fragments generated during the initiator thermal decomposition. Other charged and labile terminated amphiphilic polymer species (from triblock D synthesis) might also play a part in stabilizing the produced particles.

TEM images (Figs. 2 and S1) did not show the presence of any large micron-sized particles. This observation indicated most polymerization occurred inside micelles and not initial droplets with the later only served as monomer reservoirs. As polymerization progressed, rapidly growing micelles would likely continue to rob such droplets of both monomers and macro-RAFT copolymers, leading to their disappearance.

In our previous works $[28,29]$, triblock $\mathrm{D}$ was found to be living and effective at control molecular weights in Sty emulsion polymerizations regardless of formed morphologies. In this study, the macro-RAFT living property was only 


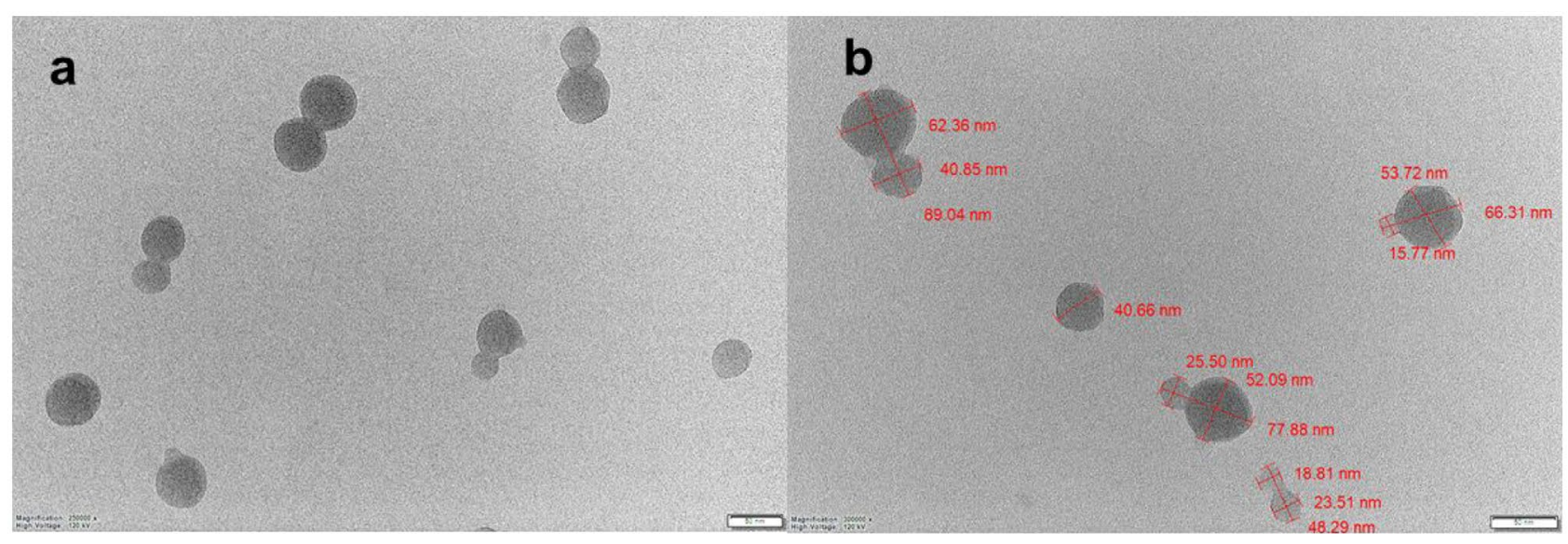

C

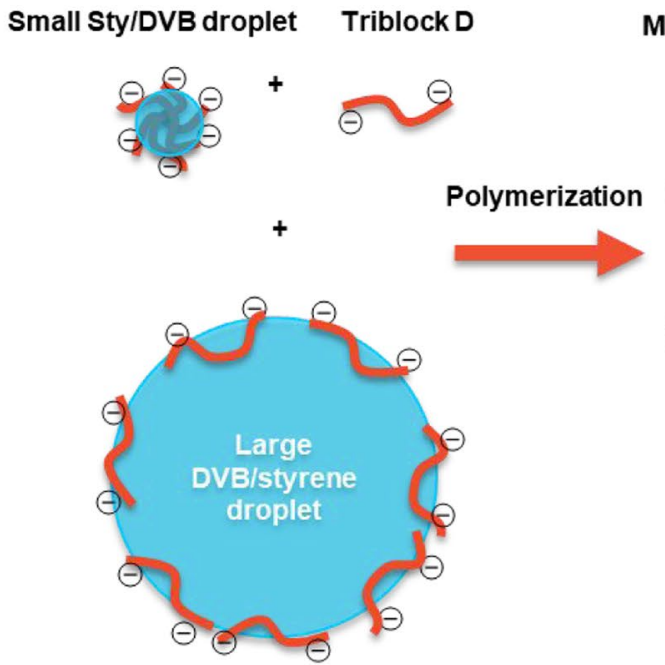

Monomer surface wetting

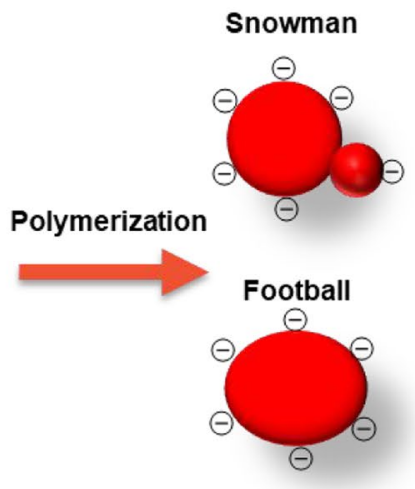

Fig. 2 a,b TEM of crosslinked PSJPs (50 nm scale bar): $\mathbf{b}$ with dimensions; $\mathbf{c}$ proposed formation mechanism of the snowman- and footballshaped nanoparticles

taken advantage of at the very early stage of particle formations. Once reacted with DVB, RAFT ends were expected to become less accessible in crosslinked polymer networks. Uncontrolled polymerization was to follow with very large, crosslinked polymers as the likely result.

\section{FFJP synthesis}

FFJPs were synthesized in the same manner as described in our recent work [27]. In this case, the crosslinked PSJPs were used as seeds in the surfactant-free free radical emulsion polymerization in which MMA/BA (1/1 by weight) was continuously fed into the reaction under stirring condition and in the presence of water soluble V501 initiator. The final latex was found to be stable, contained particles with an average particle size of $93 \mathrm{~nm}$, and produced a hazy but mostly transparent dry film. The increase in latex particle sizes and reduction in polydispersity compared to the seed latex (Table 2) indicated the absence of secondary particle formations. It also meant that added monomers were mostly consumed to form the attached polymer lobes. In Fig. 3a, a TEM image of FFJPs showed crosslinked seed components as black spheres which were surrounded by gray low-contrast film forming poly(MMA-co-BA). Digitally magnified of the same image clearly showed snowman-shaped (Fig. 3b) or football-shaped (Fig. 3c) seeds as parts of the dried individual FFJPs. The drawings in Fig. 3b, c depict top views of dried Janus particles with crosslinked seeds at the center which surrounded by the film forming polymer fringe. The surface topography of dried FFJPs, as imaged by AFM (Fig. 3d), consists of hard crosslinked seeds clearly visible, while the film forming polymer parts are spread out and merge with the substrate and neighboring particles. Cross-sectional profiles of the particles show two peaks close together, as shown a typical cross-section 
Fig. 3 a TEM micrograph of FFJPs (200 nm scale bar): b a digitally magnified two-headed snowman FFJP; $\mathbf{c}$ a digitally magnified single-headed snowman; drawings in $\mathbf{b}$ and $\mathbf{c}$ represent top views of dried FFJPs; d AFM micrograph of FFJPs on silicon wafer; e cross-sectional profile of a two-headed snowman FFJP as obtained from the AFM micrograph, on the particle enclose by the red circle in d; the two peaks are highlighted by red arrows; $\mathbf{f}$ cross-sectional profile of a single-headed snowman FFJP as obtained from the AFM micrograph, on the particle enclose by the blue circle in $\mathbf{d}$; the single peak is highlighted by a blue arrow; $\mathbf{g}$ schematic representation of the FFJP synthesis process
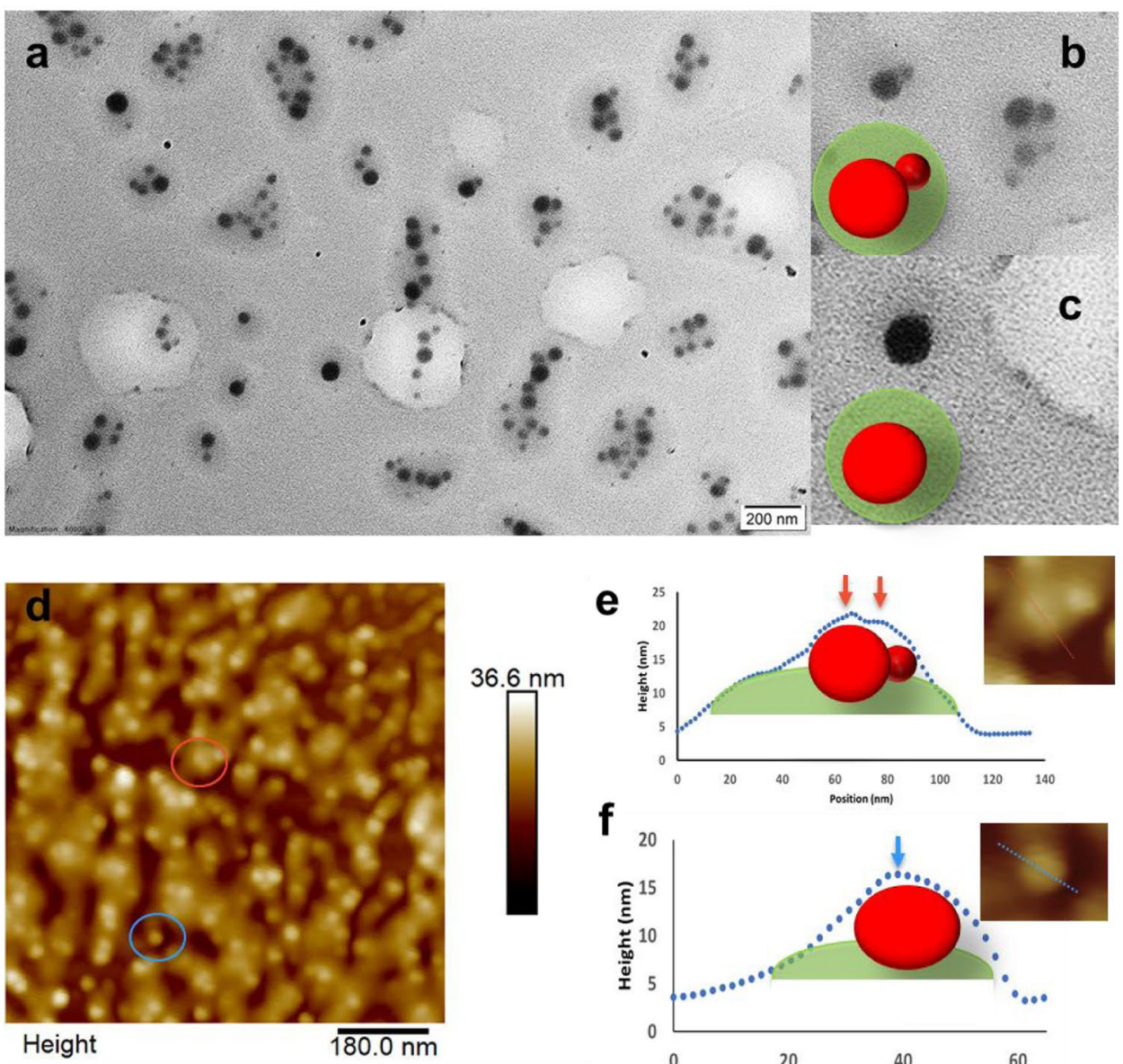

g
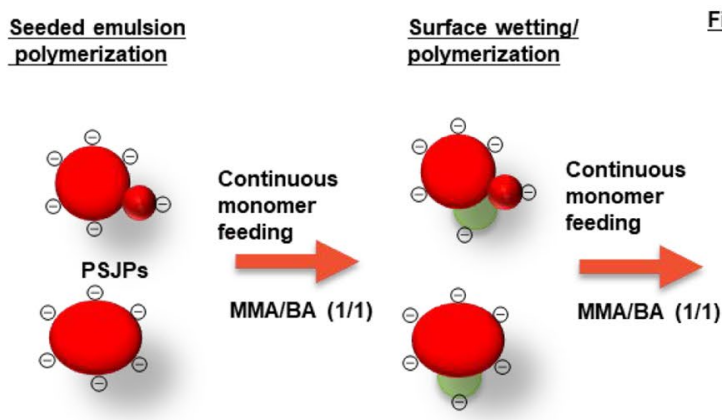

Film forming Janus particle

f
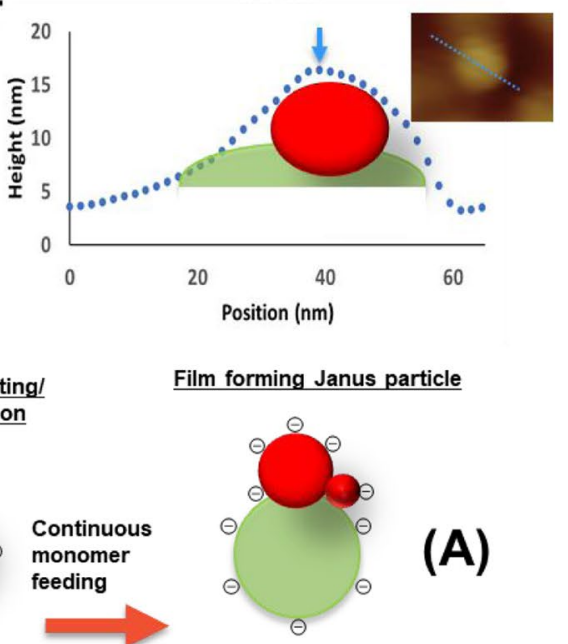

(A)

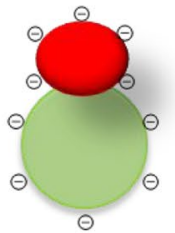

(B) in Fig. 3e. In this case, the twin adjacent peaks of different heights were probably due to horizontal arrangement of the snowman-shaped morphology as depicted in Fig. 3e. The edges of the particles in Fig. 3e are smooth, likely due to the spreading of the FFJP film-forming component (total particle diameter around $120 \mathrm{~nm}$ ). Therefore, the most likely shape was the two-headed snowman shaped as drawn in Fig. 3g(A). In Fig. 3f, the single peak cross-section profile was likely to be the traditional snowman configuration (Fig. $3 g(B)$ ) which originated from football-shaped seed particles. FFJP formation (Fig. 3g) followed the same principle of phase separation during emulsion polymerization in which crosslinked PSJP seeds forced nucleation of surface wetted monomers to produce protruded polymer lobes. In this case, monomers were supplied at a constant rate to prevent secondary particle formation and possible aggregations. Initial seed morphologies determined final FFJP shapes as two-headed (Fig. 3g(A)) or single-headed (Fig. 3g(B)) snowmen. During the polymerization, increase in particle surface area 
(due to lobe enlargement) was stabilized by the negatively charged fragments from V501 and other labile species if they were still present in the water phase. However, depletion of such charge over reaction time ensured that the newly created lobe surface would become bolder with less charge coverage as described in our previous work [27]. As the result, the synthesized Janus particles were amphiphilic with decreasing charge density gradient when moved from the seed (more negative) to the lobe (less negative).

\section{Polymer coating of calcite particles}

Calcite (calcium carbonate) is a very common inorganic extender used in water-based coating formulations [30]. It is normally used as a filler at high concentrations to reduce the use of other expensive paint components and to impart useful properties such as matting effect [30]. In this work, polymer coating of calcite particles was carried out by simple mixing of the two materials using an overhead stirrer in the presence of propylene glycol and non-ionic surfactant Teric 164. Propylene glycol was to prevent possible excessive water evaporation during mixing while Teric 164 was to enhance the coated particle overall stability just in case the stabilizing charge provided by the adsorbed FFJPs was not sufficient. After mixing and drying, thin polymer shells were observed to form on the surface. The TEM image in Fig. 4a presented a typical uniform polymer-coated calcite particle. Digitally magnified area of the same image in Fig. $4 \mathrm{~b}$ showed polymer shell thickness of between 30 and $40 \mathrm{~nm}$, indicating single layer of adsorbed FFJPs on the surface. Rough and beady surface morphology was attributed to crosslinked polymer seed components of FFJPs. Similar rough surface was also observed for polymer-coated calcite in Fig. 4c SEM (compared to the flat surface of a bare uncoated particle in Fig. S2c, SI). Based on the above evidence, the calcite polymer coating process is proposed to follow an

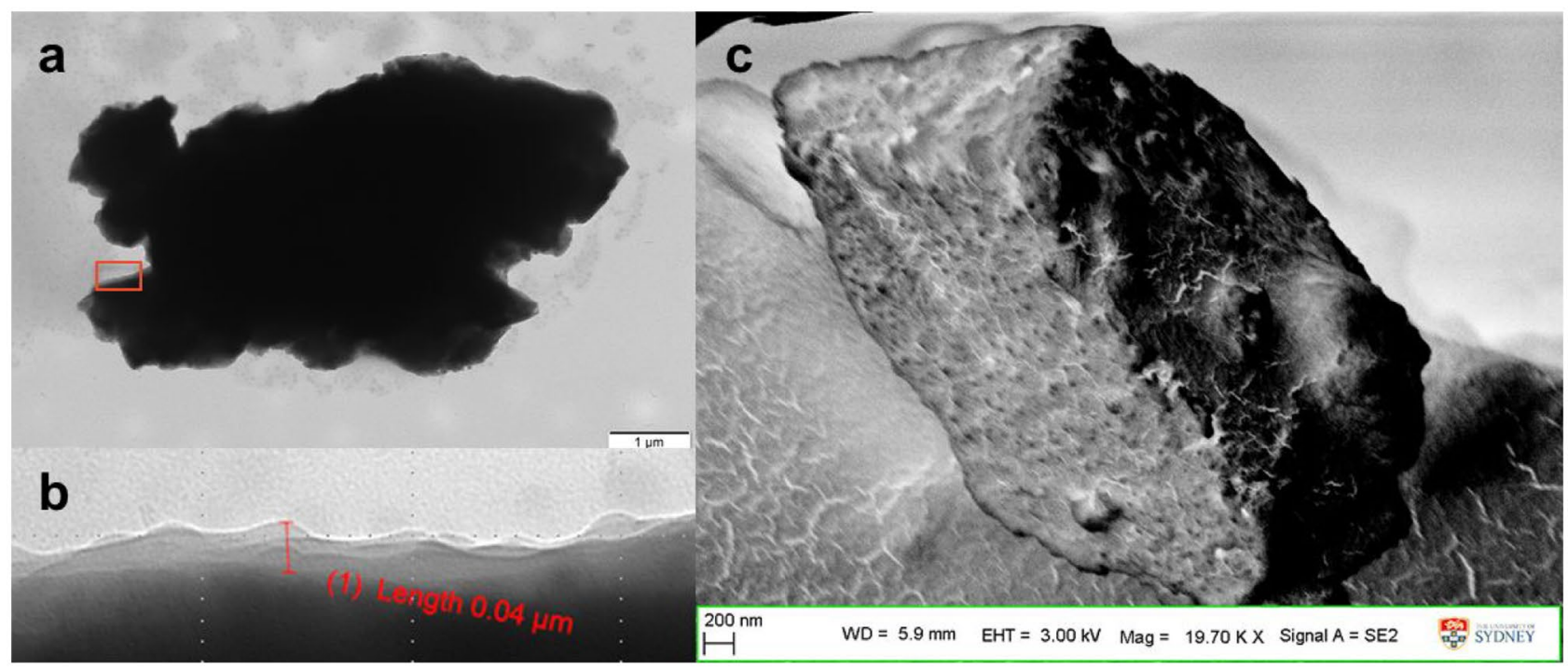

d

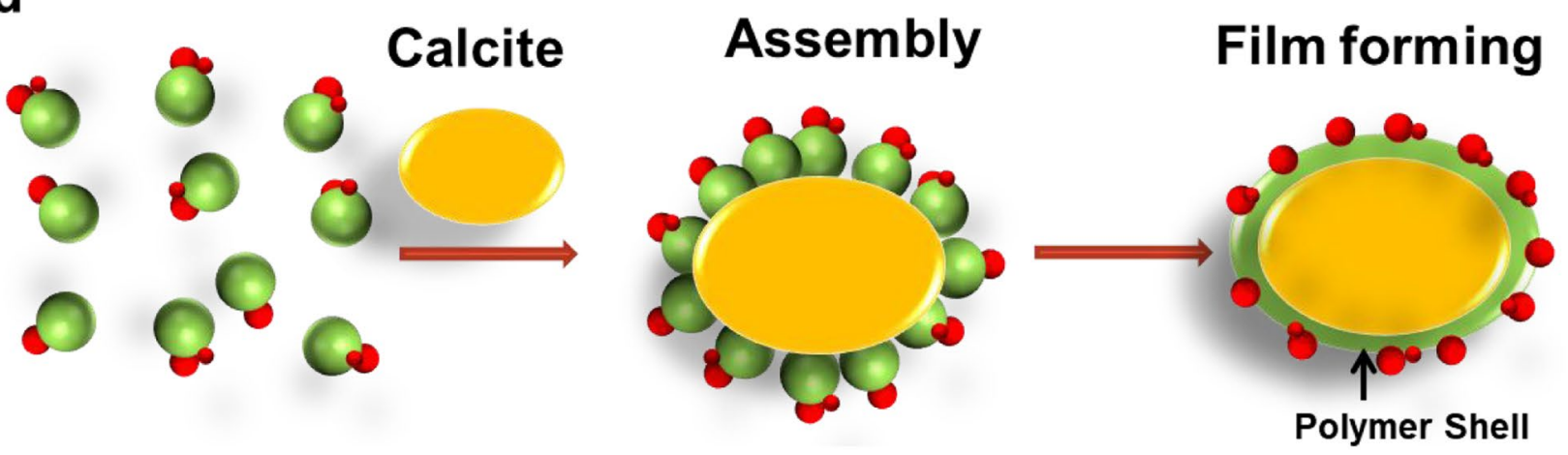

Fig. 4 a TEM of a FFJP-coated calcite particle; $\mathbf{b}$ digitally magnified image showing polymer coating layer with rough surface; $\mathbf{c}$ SEM of a FFJP-coated calcite particle; $\mathbf{d}$ scheme of polymer coating process with FFJPs 
adsorption mechanism summarized in Fig. 4d. During the mixing, FFJPs adsorbed onto surface probably via opposite charge interactions between positively charged calcite [31] and negatively charged Janus particles. The particles seemed to orient in such the way that film forming lobes adhered to the substrate while the crosslinked seeds (with their higher charge density) would expose to the water phase. During the drying, low-Tg polymer chains in the lobes flowed out and merged with each other to form continuous polymer film encapsulating the extender. On the other hand, crosslinked seed positions largely remained the same and eventually exposed to air, creating rough/ beady surface observed in Fig. $4 \mathrm{~b}$ and c. The two FFJP morphologies, single- and two-headed snowmen, were expected to display the same adsorption affinity to the calcite surface. This is because they should have similar surface charge gradients between the crosslinked seed and film forming lobe. Furthermore, our previous work with single-head FFJPs confirmed that such morphology was excellent to adsorb and coat a variety of solid particle surfaces [27]. There was a clear difference in particle adsorption behavior between PSJPs and FFJPs. SEMs in Fig. S2a and b showed PSJPs did adsorb onto the calcite but in a random fashion with large, uncovered surface gaps between them. This was attributed to the lack of film forming materials which could spread, merge, and close those gaps. Observed gaps was also due to the higher charge density on PSJPs which led to stronger same charge expulsion between particles (more stable in dispersed phase) as normally associated with heterogenous assembly systems [32-34]. Electrostatic expulsions prevented PSJPs from being closely packed when they approached and interacted with the extender surface during the dispersion. The presence of such surface gaps makes the calcite susceptible to chemicals and limit potential applications of the PSJP latex as a standalone material.

In the absence of Teric 164, polymer coating of calcite particles was found to be the similar. TEM and SEM in Fig. S3 showed uniform polymer-coated Omyacarb particle which were obtained by the same mixing method but without the surfactant. While this work has been geared towards water-based coating formulations, the ability to coat solid particles with or without extra stabilizers offers additional flexibility to the technique and broadens its appeal.

\section{Conclusions}

In this work, a simple method to synthesize Janus particles by free radical emulsion polymerization using RAFT has been presented. The crosslinked polystyrene Janus latex containing both snowman- and football-shaped particles was first synthesized by a one-step batch process with triblock
D macro-RAFT copolymers as the stabilizers. Such particles were then used as seeds in a continuous free radical emulsion polymerization process to produce film forming polymer Janus binder latex containing both single- and twoheaded snowman-shaped particles. The final latex was effective in uniformly coating calcite extender particles, forming thin encapsulating polymer shells with the hard crosslinked polymer seeds exposed to the air polymer interface after drying. The synthesis is simple and offers tremendous potential for industrial scale-up.

Supplementary Information The online version contains supplementary material available at https://doi.org/10.1007/s00396-021-04939-x.

Acknowledgements Financial support from DuluxGroup Australia and the ARC Linkage Scheme are gratefully acknowledged. The authors also acknowledge the facilities and technical assistance of the Australian Centre for Microscopy and Microanalysis, the University of Sydney. The Key Centre for Polymers and Colloids was established and supported under the Australian Research Council's Research Centers Program. Prof Chiara Neto is acknowledged for useful discussions and Dr Liwen Zhu is thanked for providing the AFM micrographs. Dr Minh Lam is thanked for imaging assistance.

Funding Open Access funding enabled and organized by CAUL and its Member Institutions. This study was funded by DuluxGroup Australia and Australian Research Council in the form of ARC Linkage Scheme (LP170100090).

\section{Declarations}

Conflict of interest The authors declare no competing interests.

Open Access This article is licensed under a Creative Commons Attribution 4.0 International License, which permits use, sharing, adaptation, distribution and reproduction in any medium or format, as long as you give appropriate credit to the original author(s) and the source, provide a link to the Creative Commons licence, and indicate if changes were made. The images or other third party material in this article are included in the article's Creative Commons licence, unless indicated otherwise in a credit line to the material. If material is not included in the article's Creative Commons licence and your intended use is not permitted by statutory regulation or exceeds the permitted use, you will need to obtain permission directly from the copyright holder. To view a copy of this licence, visit http://creativecommons.org/licenses/by/4.0/.

\section{References}

1. Zetterlund PB, Kagawa Y, Okubo M (2008) Controlled/living radical polymerization in dispersed systems. Chem Rev 108(9):3747-3794

2. Moribe H, Kitayama Y, Suzuki T, Okubo M (2011) Emulsifierfree, organotellurium-mediated living radical emulsion polymerization of styrene: effect of stirring rate. Macromolecules 44(2):263-268

3. Kitayama Y, Chaiyasat A, Minami H, Okubo M (2010) Emulsifier-free, organotellurium-mediated living radical emulsion polymerization of styrene: polymerization loci. Macromolecules 43(18):7465-7471 
4. Saito N, Takekoh R, Nakatsuru R, Okubo M (2007) Effect of stabilizer on formation of "onionlike" multilayered polystyrene-blockpoly(methyl methacrylate) particles. Langmuir 23(11):5978-5983

5. Fujibayashi T, Okubo M (2007) Preparation and thermodynamic stability of micron-sized, monodisperse composite polymer particles of disc-like shapes by seeded dispersion polymerization. Langmuir 23(15):7958-7962

6. Kobayashi H, Miyanaga E, Okubo M (2007) Preparation of multihollow polymer particles by seeded emulsion polymerization using seed particles with incorporated nonionic emulsifier. Langmuir 23(17):8703-8708

7. Minami H, Kobayashi H, Okubo M (2005) Preparation of hollow polymer particles with a single hole in the shell by SaPSeP. Langmuir 21(13):5655-5658

8. Schmid A, Fujii S, Armes SP, Leite CAP, Galembeck F, Minami H, Saito N, Okubo M (2007) Polystyrene-silica colloidal nanocomposite particles prepared by alcoholic dispersion polymerization. Chem Mater 19(10):2435-2445

9. Yamagami T, Kitayama Y, Okubo M (2014) Preparation of stimuliresponsive "mushroom-like" janus polymer particles as particulate surfactant by site-selective surface-initiated AGET ATRP in aqueous dispersed systems. Langmuir 30(26):7823-7832

10. Yamashita N, Konishi N, Tanaka T, Okubo M (2012) Preparation of hemispherical polymer particles by cleavage of a Janus poly(methyl methacrylate)/polystyrene composite particle. Langmuir 28(35):12886-12892

11. Tanaka T, Okayama M, Minami H, Okubo M (2010) Dual stimuliresponsive "mushroom-like" Janus polymer particles as particulate surfactants. Langmuir 26(14):11732-11736

12. Tanaka T, Okayama M, Kitayama Y, Kagawa Y, Okubo M (2010) Preparation of "mushroom-like" Janus particles by site-selective surface-initiated atom transfer radical polymerization in aqueous dispersed systems. Langmuir 26(11):7843-7847

13. Ahmad H, Saito N, Kagawa Y, Okubo M (2008) Preparation of micrometer-sized, monodisperse "janus" composite polymer particles having temperature-sensitive polymer brushes at half of the surface by seeded atom transfer radical polymerization. Langmuir 24(3):688-691

14. Saito N, Nakatsuru R, Kagari Y, Okubo M (2007) Formation of "snowmanlike" polystyrene/poly(methyl methacrylate)/toluene droplets dispersed in an aqueous solution of a nonionic surfactant at thermodynamic equilibrium. Langmuir 23(23):11506-11512

15. Saito N, Kagari Y, Okubo M (2007) Revisiting the morphology development of solvent-swollen composite polymer particles at thermodynamic equilibrium. Langmuir 23(11):5914-5919

16. Okubo M, Saito N, Fujibayashi T (2005) Preparation of polystyrene/poly(methyl methacrylate) composite particles having a dent. Colloid Polym Sci 283(6):691-698

17. Wurm F, Kilbinger AF (2009) Polymeric janus particles. Angew Chem Int Ed Engl 48(45):8412-8421

18. Sheu HR, El-Aasser MS, Vanderhoff JW (1990) Phase separation in polystyrene latex interpenetrating polymer networks. J Polym Sci, Part A: Polym Chem 28(3):629-651

19. Mock EB, De Bruyn H, Hawkett BS, Gilbert RG, Zukoski CF (2006) Synthesis of anisotropic nanoparticles by seeded emulsion polymerization. Langmuir 22(9):4037-4043

20. Kim J-W, Lee D, Shum HC, Weitz DA (2008) Colloid surfactants for emulsion stabilization. Adv Mater 20(17):3239-3243
21. Kim J-W, Larsen RJ, Weitz DA (2006) Synthesis of nonspherical colloidal particles with anisotropic properties. J Am Chem Soc 128(44):14374-14377

22. Lan Y, Choi J, Li H, Jia Y, Huang R, Stebe KJ, Lee D (2019) Janus particles with varying configurations for emulsion stabilization. Ind Eng Chem Res 58(46):20961-20968

23. Liu Y, Jiang K, Ma Y, Liu L, Yang W (2016) Control of crosslinking and reactions in one-step dispersion polymerization toward particles with combined anisotropies. Polym Chem-Uk 7(15):2728-2739

24. Lotierzo A, Meaney SP, Bon SAF (2019) Effect of the addition of salt to Pickering emulsion polymerizations using polymeric nanogels as stabilizers. Polym Chem-Uk 10(48):6600-6608

25. Lotierzo A, Longbottom BW, Lee WH, Bon SAF (2019) Synthesis of Janus and patchy particles using nanogels as stabilizers in emulsion polymerization. ACS Nano 13(1):399-407

26. Pham BTT, Such CH, Hawkett BS (2015) Synthesis of polymeric janus nanoparticles and their application in surfactant-free emulsion polymerizations. Polym Chem-Uk 6(3):426-435

27. Nguyen D, Zhu L, Huynh VT, Azniwati A-A, Pham NTH, Lam MT, Serelis AK, Davey T, Such C, Neto C, Hawkett BS (2020) Soft-hard Janus nanoparticles for polymer encapsulation of solid particulate. Polym Chem-Uk 11(35):5610-5618

28. Nguyen D, Huynh V, Lam M, Serelis A, Davey T, Paravagna O, Such C, Hawkett B (2021) Encapsulation by directed PISA: RAFT-based polymer-vesiculated pigment for opacity enhancement in paint films. Macromol Rapid Commun 42(10):2100008

29. Nguyen D, Huynh V, Pham N, Pham B, Serelis A, Davey T, Such C, Hawkett B (2019) SPION-decorated nanofibers by RAFTmediated free radical emulsion polymerization-induced self assembly. Macromol Rapid Commun 40(2):1800402

30. Al Mahrouqi D, Vinogradov J, Jackson MD (2017) Zeta potential of artificial and natural calcite in aqueous solution. Adv Colloid Interface Sci 240:60-76

31. Eriksson R, Merta J, Rosenholm JB (2007) The calcite/water interface: I. Surface charge in indifferent electrolyte media and the influence of low-molecular-weight polyelectrolyte. Journal of Colloid and Interface Science 313(1):184-193

32. Wang Y, Chen G, Yang M, Silber G, Xing S, Tan LH, Wang F, Feng Y, Liu X, Li S, Chen H (2010) A systems approach towards the stoichiometry-controlled hetero-assembly of nanoparticles. Nat Commun 1(1):87

33. Li G, Yang X, Bai F, Huang W (2006) Raspberry-like composite polymer particles by self-assemble heterocoagulation based on a charge compensation process. J Colloid Interface Sci 297(2):705-710

34. Ha Eun L, Kyu Hwan C, Xia M, Dong Woo K, Bum Jun P (2020) Interactions between polystyrene particles with diameters of several tens to hundreds of micrometers at the oil-water interface. J Colloid Interface Sci 560:838-848

Publisher's Note Springer Nature remains neutral with regard to jurisdictional claims in published maps and institutional affiliations. 